\title{
COLONIALISMO E TEORIA GERAL DO DIREITO: DIÁLOGOS COM A HISTÓRIA DO BRASIL A PARTIR DA VIDA NEGADA
}

\section{André Ribeiro Giamberardino}

Estudante de Graduação em Direito na Universidade Federal do Paraná.

RESUMO: A violência da colonização e as premissas eurocêntricas da Modernidade compuseram na realidade brasileira um sistema jurídico que teve desde sua gênese a finalidade precípua de manutenção das relações de exploração estabelecidas entre centro e periferia, por meio da transposição autoritária dos dogmas da Teoria Geral do Direito ocidental, especialmente no que tange ao monopólio do Estado na produção e validação das normas jurídicas e à individualização dos conflitos. Reconhece-se a permanente crise de legitimidade do Direito latino-americano, principalmente em relação a suas fontes formais, sendo necessária a identificação do caráter negativo do mito da Modernidade e seu papel na rejeição da pluralidade de ordens jurídicas em prol do monismo estatal. Opta-se, em seguida, pela adoção dos critérios de validade descritos por Enrique Dussel na Ética da Libertação, pautados pela necessidade material de produção e reprodução da vida humana, a fim de se vislumbrarem horizontes que permitam a reinvenção da emancipação social desde a perspectiva das vítimas intencionais e não-intencionais do sistema vigente, tanto no resgate da racionalidade comunitária presente nas culturas indígena e africana, como no reconhecimento da legitimidade dos movimentos sociais críticos como sujeitos coletivos que lutam pela criação de "novos direitos", segundo suas necessidades concretas de sobrevivência.

PALAVRAS-CHAVE: Modernidade e transmodernidade; América Latina; História do direito no Brasil; Filosofia da libertação; Teoria geral do direito; Pluralismo; Alternatividade jurídica. 


\section{INTRODUÇÃO}

A formação do povo brasileiro não aconteceu mediante a evolução das relações de sociabilidade de uma população anteriormente reunida; sucedeu-se, em seu lugar, um choque traumático que resultou na fusão de matrizes raciais e tradições culturais distintas, interrompendo o desenvolvimento autônomo de povos nativos detentores de suas próprias culturas e métodos de organização.

Diante de uma gigantesca heterogeneidade étnica original, ${ }^{1}$ Ribeiro observa que a principal "obra colonial" de Portugal não foi apenas a exploração de riquezas naturais ou a exportação de matéria-prima, mas a gestação de um povo-nação de forma especialmente peculiar, caracterizado, no aspecto econômico, por uma forma renovada de escravismo cuja produção se voltou apenas ao enriquecimento da metrópole; ${ }^{2}$ e no aspecto cultural, pela mestiçagem das bagagens européias, indígenas e africanas, sendo as duas últimas violentamente subjugadas à primeira. ${ }^{3}$ Permanece nítida, hoje, a contradição inerente ao processo de unificação de um povo tão diverso em sua origem,

(...) opondo à unidade de um denominador cultural comum, com que se identifica um povo de 160 milhões de habitantes, a dilaceração desse mesmo povo por uma estratificação classista de nítido colorido racial e do tipo mais cruamente desigualitário que se possa conceber. ${ }^{4}$

O descobrimento e a colonização do Brasil fundaram-se na transferência de suas riquezas naturais à metrópole ${ }^{5}$ e na exploração da mão-de-obra indígena, em um primeiro momento, e da africana durante centenas de anos, restando evidente que a construção do sistema jurídico teria por finalidade precípua a viabilização dos

${ }^{1}$ RIBEIRO, Darcy. O Povo Brasileiro, p.68.

${ }^{2}$ Nesse sentido aponta lanni para o fato de que apenas uma pequena parte do excedente gerado nas colônias nelas permanecia, concluindo que "tanto por meio das administrações metropolitanas nas colônias, como por intermédio das empresas e do comércio privado, as exportações coloniais excediam às importações" (IANNI, Octavio, Escravidão e Racismo, p.7).

\footnotetext{
${ }^{3}$ WOLKMER, Antônio Carlos. História do Direito no Brasil, p.46.

${ }^{4}$ RIBEIRO, Darcy. O Povo Brasileiro, p.24.
} 
propósitos mercantis que, seja enquanto Colônia, Império ou República, sempre se pautaram pelo atendimento a interesses externos. A história das relações jurídicas na América Latina é, assim, "a história dos povos colonizados, marcada pelo genocídio, pelo escravismo recente, pela rapinagem de seus produtos e de sua força de trabalho, pela profunda diferenciação de classes (...)". A formação do Poder Judiciário, por sua vez, condicionou-se à burocracia profissionalizada exigida por Portugal e às relações pessoais de parentesco que encerravam qualquer possibilidade de imparcialidade.

Nessas circunstâncias, é necessária uma interpretação da legalidade que seja contextualizada historicamente e considerada em sua relatividade, visto que a validade do sistema vem tornar-se não-validade perante a multidão de excluídos dos processos políticos oficiais que transformaram a sociedade brasileira no curso de sua história.

\section{COLONIALISMO, MODERNIDADE EUROPÉIA E A REJEIÇÃO DA PLURALIDADE}

Se a construção do sistema jurídico nacional aconteceu nos séculos em que mais se desenvolveu e predominou no mundo ocidental o paradigma da Modernidade, é imprescindível que o ponto de partida seja a percepção de que se

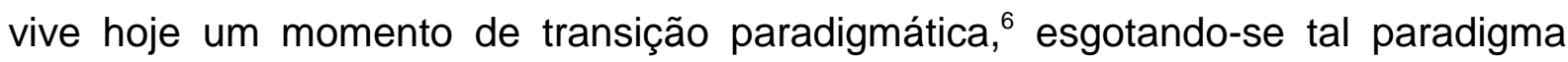

${ }^{5}$ É a América Latina a região das veias abertas: "Desde o descobrimento até nossos dias, tudo se transformou em capital europeu, ou, mais tarde, norte-americano, e como tal tem se acumulado e se acumula até hoje nos distantes centros de poder. (...). Nossa derrota esteve sempre implícita na vitória alheia, nossa riqueza gerou sempre a nossa pobreza para alimentar a prosperidade dos outros: os impérios e seus agentes nativos. $\mathrm{Na}$ alquimia colonial e neo-colonial, o ouro se transforma em sucata e os alimentos se convertem em veneno." (GALEANO, Eduardo. As Veias Abertas da América Latina, p.14).

${ }^{6}$ Por paradigma entende-se o significado empregado por Thomas Kuhn, como uma constelação de crenças, valores e técnicas partilhadas pelos membros de uma determinada comunidade, assim como as soluções empregadas como modelo para resolução de problemas. Por meio desta teoria Kuhn demonstra que o desenvolvimento do conhecimento científico não acontece de modo "cumulativo e contínuo"; ocorre, ao contrário, de maneira descontínua, mediante revoluções científicas: sendo a "ciência normal" o paradigma pacificamente aceito pela comunidade científica, e "ciência revolucionária" a que se instaura em momentos de crise, quando se acumulam situações para as quais o paradigma hegemônico não oferece respostas satisfatórias. (KUHN, Thomas. A Estrutura das Revoluções Científicas, p.218). A passagem de um paradigma para outro não acontece sob um processo contínuo e previsível, mas é, segundo Boaventura de Sousa Santos, "semi-cega e semiinvisível", na medida em que só muito tempo após a morte de um paradigma sociocultural é possível confirmá-la com segurança. (SANTOS, Boaventura de Sousa. A Crítica da Razão Indolente, p.15). Considerando que cada paradigma produz suas próprias condições de cientificidade, a mudança significa uma reconstrução destas condições e da própria "inteligibilidade do real" proporcionada pelo paradigma anterior. (LUDWIG, Celso Luiz. Paradigmas da Filosofia, p.5, citando também SANTOS, Boaventura de Sousa. Introdução a uma ciência pósmoderna. Rio de Janeiro: Graal, 1989, p.18). 
enquanto pensamento hegemônico. Não há uma data certa de nascimento para o paradigma "Moderno", pois se trata de um processo histórico de formação difusa, lenta e complexa. ${ }^{7}$ Mas é possível afirmar, segundo Fonseca, que sua gestação pode ser remetida às transformações ocorridas desde os séculos $\mathrm{X}$ e $\mathrm{XI}$, "com o lento e irregular avanço do mercado de trocas comerciais e a aceleração de um processo de racionalização que até então era muito lento". ${ }^{8}$

Entre os aspectos decorrentes da influência do paradigma Moderno sobre todo o mundo ocidental, destaca-se, primeiramente, a pretensão de exclusivismo epistemológico do conhecimento científico, em detrimento de diversas outras formas de conhecimento que foram "colonizadas" e rejeitadas; e em segundo lugar, no que tange diretamente à formação do Direito na América Latina, a construção de teorias jurídicas ligadas inicialmente ao direito natural, de viés religioso e salvacionista, justificando a doutrinação dos índios e a escravidão dos africanos, ${ }^{9}$ e em seguida ao positivismo jurídico, matriz fundamental da dogmática jurídica que compõe a tradicional Teoria Geral do Direito ocidental.

O esgotamento da Modernidade invoca questionar-se o que vem em seu lugar. Para Boaventura de Sousa Santos, o caminho que se vislumbra pode ser denominado "ciência pós-moderna", devendo, primeiramente, ser esclarecida a distinção entre diferentes concepções de pós-modernismo. A primeira, hegemônica, é fruto do pensamento dominante no Primeiro Mundo, recusando a racionalidade da Modernidade, mas redundando, "paradoxalmente, na celebração da sociedade que ela tinha conformado", ${ }^{10}$ resultando em uma nova forma de opressão social pela indiferença. ${ }^{11}$ Como contraposição a essa postura tem-se o "pós-modernismo de

${ }^{7}$ FONSECA, Ricardo Marcelo. Modernidade e Contrato de Trabalho, p.30.

8 Idem.

9 RIBEIRO, DARCY. Op.cit., p.59: "Esse era um mandato imperativo no plano espiritual. Uma destinação expressa, uma missão a cargo da Coroa, cujo direito de avassalar os índios, colonizar e fluir as riquezas da terra nova decorria do sagrado dever de salvá-los pela evangelização".

10 SANTOS, Do Pós-Moderno ao Pós-Colonial. E para além de um e outro, p.4.

11 Boaventura de Sousa Santos (idem, p.9-11) conceitua o que seria, basicamente, o pós-modernismo reacionário: "(1) crítica do universalismo e da unilinearidade da história traduzida em conceitos como progresso, desenvolvimento ou modernização (...); (2) renúncia a projetos coletivos de transformação social, sendo a emancipação social um mito sem consistência; (3) celebração, por vezes melancólica, do fim da utopia, do ceticismo na política e da paródia na estética; (4) concepção da crítica como desconstrução; (5) relativismo ou sincretismo cultural; (6) ênfase na fragmentação, nas margens ou nas periferias, na heterogeneidade e na pluralidade (...)". 
oposição", cujo principal escopo é a necessidade de se reinventar a emancipação social.

Para Dussel, deve-se buscar o horizonte da "transmodernidade", o que permite a crítica ao projeto moderno sem eliminar suas potencialidades, sob uma ótica que inclua a perspectiva da periferia e não apenas do Norte do mundo. ${ }^{12}$

O próprio Boaventura admite que os "pilares da Modernidade" por ele teorizados não servem, por si só, à realidade latino-americana:

a regulação social assente em três princípios - o princípio do Estado, do mercado e da comunidade - não dá conta das formas de (des)regulação colonial onde o Estado é estrangeiro, o mercado inclui pessoas entre as mercadorias (os escravos) e as comunidades são arrasadas em nome do capitalismo e da missão civilizadora, e substituídas por uma minúscula sociedade civil racializada, criada pelo Estado e constituída por colonos, pelos seus descendentes e por minúsculas minorias de assimilados. ${ }^{13}$

De qualquer forma, tanto Santos como Dussel consideram que qualquer reconstrução somente será possível se surgir das experiências das próprias vítimas da modernidade ocidental. São estas, nas palavras de Boaventura, os "grupos sociais que tinham sofrido com o exclusivismo epistemológico da ciência moderna e com a redução das possibilidades emancipatórias da modernidade ocidental às tornadas possíveis pelo capitalismo moderno"; 14 ou nas palavras de Dussel, "os Outros encobertos pelo descobrimento, os oprimidos das nações periféricas (que sofrem então uma dupla dominação), (...); a 'outra face' que pagou com sua morte a acumulação do capital original, o desenvolvimento dos países centrais". ${ }^{15}$

A descoberta da América - o "Novo Mundo" - pelos europeus em 1492 tem importância central na compreensão da Modernidade ${ }^{16}$ e na explicação do modo pelo qual a Europa readquiriu a posição de centro do mundo, perdida para os

12 LUDWIG, Celso Luiz. Da Ética à Filosofia Política Crítica na Transmodernidade: reflexões desde a Filosofia de E. Dussel. FONSECA, Ricardo Marcelo (Org.). Repensando a Teoria do Estado, p.285.

13 SANTOS, Do Pós-Moderno ao Pós-Colonial. E para além de um e outro, p.14.

14 SANTOS, Do Pós-Moderno ao Pós-Colonial. E para além de um e outro, p.6.

15 DUSSEL, Enrique. 1492 - O Encobrimento do Outro, p.159/172. Ressalte-se que o termo "Sul" refere-se à concepção de Sul como metáfora do sofrimento produzido pela Modernidade, distinguindo-se do Sul "rico" e Imperial, resultado da relação colonial capitalista. (SANTOS, Do Pós-Moderno ao Pós-Colonial. E para além de um e outro, p.18).

16 "A modernidade originou-se nas cidades européias medievais, livres, centros de enorme criatividade. Mas 'nasceu' quando a Europa pôde se confrontar com o seu 'Outro' e controlá-lo, vencê-lo, violentá-lo" (DUSSEL, idem, p.8). 
muçulmanos nos séculos anteriores, constituindo uma nova subjetividade - a subjetividade moderna -, a partir de domínio, conquista e controle exercidos sobre um Outro diferente, porém negado em sua diversidade.

No momento em que se iniciaram as grandes navegações, a América Latina estava ainda completamente fora da história e do contexto político. Dentro da totalidade européia, o mundo sempre foi Europa, Ásia e África, unidos pelo Mar Mediterrâneo, sendo o papel dos dois últimos explicitamente declarados inferior ao desempenhado pelo mundo europeu. Nesse sentido, Dussel cita Hegel, cuja obra afirma sem meandros que os africanos seriam "facilmente fanatizados", que a África seria "algo isolado e sem história"; ou que a Ásia desempenharia papel introdutório e "infantil" no desenvolvimento da História Mundial. ${ }^{17}$ A cultura européia nada teria a aprender ou apreender de outras culturas, pressupondo sua própria completude. No mesmo sentido se revelará a percepção kantiana do lluminismo, como "a saída por si mesma da humanidade de um estado de imaturidade culpável", ${ }^{18}$ argumento basilar do discurso da inferioridade dos povos não-europeus.

Observe-se que, após a descoberta de novas terras, o navegador Cristóvão Colombo morre acreditando ter chegado a terras asiáticas. Não à toa construiu a representação de um "ser asiático" ao deparar-se com os indígenas, que nunca foram, portanto, descobertos na novidade de sua diversidade, mas logo identificados como um "si mesmo" já conhecido, o asiático. ${ }^{19}$ Tiveram, desde o primeiro contato, sua identidade encoberta por uma invenção da imaginação dos próprios navegantes europeus. No momento em que se toma consciência do caráter inédito do lugar, chamado de "uma Quarta parte da Terra", o europeu projeta a si mesmo no Outro através do domínio e da conquista, sem reconhecer-lhe sua alteridade: "os habitantes das novas terras descobertas não aparecem como Outros, mas como o Si-mesmo a ser conquistado, colonizado, modernizado, civilizado, como 'matéria' do ego moderno."20

Pode-se definir "eurocentrismo", portanto, como a subsunção e incorporação do Outro à Totalidade européia como objeto. Por isso afirma-se que a Modernidade

\footnotetext{
17 DUSSEL, op.cit, p.20.

${ }^{18}$ DUSSEL, op.cit, p.17.

${ }^{19}$ DUSSEL, op. cit, p.32.
} 
européia apresenta, duplamente, um conteúdo positivo e outro negativo. O primeiro seria a emancipação racional pretendida com a passagem do teocentrismo para 0 antropocentrismo, com a consagração da "autonomia da vontade" e do "sujeito de direito" como expressões de um novo paradigma, fundado na Razão e exprimido na visão cartesiana como "a firme crença na certeza do conhecimento científico, (...), obtido pela intuição e dedução" ${ }^{21}$ O conteúdo negativo, ${ }^{22}$ por sua vez, parte do conceito kantiano, já citado, de "imaturidade culpável", um modo de vida concebido como bárbaro ou não desenvolvido, que deveria obrigatoriamente integrar-se ao processo civilizador. A civilização moderna e cristã, supostamente superior e mais desenvolvida, vê como uma exigência moral o desenvolvimento e a catequização dos que ainda se encontram nesse estado de imaturidade, sendo justificável o exercício da violência como um "sacrifício necessário" para alcançar o objetivo do desenvolvimento e da salvação espiritual.

Assim, o mito da Modernidade é a justificação de uma práxis irracional de violência na "culpa" das próprias vítimas (a culpa de se oporem ao processo civilizador), inocentando-se a práxis moderna do genocídio ocorrido em todo esse período. A transmodernidade significa negar tal inocência e afirmar para as vítimas a "sua Alteridade como Identidade na Exterioridade, como pessoas que foram negadas pela Modernidade", ${ }^{23}$ não negando a razão em si, mas a razão como justificativa de uma violência irracional e injustificável.

Por isso se afirma a possibilidade de se encontrar, nos sistemas jurídicos de povos historicamente massacrados, exemplos reais de modos de vida bemsucedidos durante milênios até sua destruição no encontro com a "civilização ocidental-capitalista", em uma "escavação arqueológica" que investigue

no lixo cultural produzido pelo cânone da modernidade ocidental para descobrir as tradições e alternativas que dele foram expulsas; escavar no colonialismo e no neocolonialismo para

${ }^{20}$ DUSSEL, op. cit, p.36.

${ }^{21}$ LUDWIG, Celso Luiz. A Alternatividade Jurídica na Perspectiva da Libertação: uma leitura a partir da filosofia de Enrique Dussel, p.28.

${ }^{22}$ Ver DUSSEL, op. cit,p.185-188.

${ }^{23}$ DUSSEL, op. cit, p.187. 
descobrir nos escombros das relações dominantes entre a cultura ocidental e outras culturas outras possíveis relações mais recíprocas e igualitárias. ${ }^{24}$

Assevera ainda Santos que a "rejeição arbitrária da pluralidade de ordens jurídicas eliminou ou reduziu drasticamente o potencial emancipatório do direito moderno" ${ }^{25}$ A violência da colonização na América Latina - o encobrimento do Outro e das possibilidades de racionalidades alternativas - e a necessidade de superar as conseqüências do colonialismo condicionam um novo ponto de partida para a efetiva reinvenção da emancipação social: a exterioridade das vítimas, conforme uma ética que reconheça sua existência negada e sua necessidade de produção e reprodução da própria vida.

\section{PERSPECTIVA DA TEORIA GERAL DO DIREITO NO OCIDENTE}

O Direito ocidental moderno tem sua gênese na transição da economia feudal para o capitalismo mercantil, a partir dos princípios da filosofia liberal européia. Paralelamente ao renascimento das cidades e do comércio constrói-se a família de direito romano-germânica, tomando-se novamente a "consciência de que só o direito pode assegurar a ordem e a segurança necessárias ao progresso". ${ }^{26}$ Abandona-se, assim, a descentralização do poder e o pluralismo de ordenamentos jurídicos, em busca de unificação dos territórios, a fim de permitir a formação de um Estado Nacional, soberano e detentor do monopólio de produção das normas jurídicas.

O princípio da legalidade, portanto, é resultado de um projeto eminentemente estatal, validado e aplicado pelo próprio Estado mediante de procedimentos altamente formais. ${ }^{27}$ Tendo uma finalidade política, qual seja, a garantia da nova ordem político-econômica, passou-se da defesa do jusnaturalismo para o juspositivismo com naturalidade, apesar de serem concepções, em princípio, antagônicas. Na verdade, afirma Mascaro que ambas as filosofias

\footnotetext{
24 SANTOS, Boaventura de Sousa. A Crítica da Razão Indolente, p.18.

${ }^{25}$ SANTOS, Boaventura de Sousa. A Crítica da Razão Indolente, p.172.

26 DAVID, Renè. Os Grandes Sistemas do Direito Contemporâneo, p.31.

${ }^{27}$ WOLKMER, Antônio Carlos. Pluralismo Jurídico, p.49.
} 
tratam ao mesmo tempo dos mesmos conteúdos e da mesma aposta na igualdade, na universalidade, na estabilidade das leis. (..). A diferença reside no exato período em que o poder político-estatal era absolutista para a sua transformação em poder burguês. Em quinze anos - de 1789 a 1804 - aquilo que era a declaração filosófica das leis universais do homem já era código civil positivado na França. ${ }^{28}$

Destaque-se, nesse sentido, que Bobbio coloca o fato de diversos escritores dos séculos XVII e XVIII apresentarem o direito natural como uma função subrogatória, ou seja, como mecanismo de suprimento das eventuais lacunas do direito positivo. ${ }^{29}$

A partir da prevalência do positivismo jurídico, o princípio da legalidade preconiza a fundação do Direito em normas gerais abstratas, fixadas por meio de procedimentos pré-definidos, e não em comandos individuais, ${ }^{30}$ buscando previsibilidade, segurança, estabilidade às relações sociais e, principalmente, à tensão entre a liberdade individual e o poder punitivo do Estado.

Os fundamentos do juspositivismo que sustentam o paradigma da dogmática jurídica $^{31}$ permitem a obtenção de um panorama acerca da racionalidade predominante em todo o processo de formação do Direito ocidental; e suas conseqüências na transposição desta que é uma proposta européia para as sociedades periféricas e ex-colônias como o Brasil.

A primeira característica marcante é a identidade firmada entre Estado e Direito, pressuposto do processo histórico que conferiu ao Estado soberano a prerrogativa de criar legalidade com exclusividade, seja diretamente, mediante 0

${ }^{28}$ MASCARO, Alysson Leandro. Crítica da Legalidade e do Direito Brasileiro, p.48.

${ }^{29}$ BOBBIO afirma o seguinte: "Esta solução é perfeitamente lógica para quem admite que o direito positivo se funda (através do Estado e do contrato social que faz surgir este último do estado de natureza) no direito natural: vindo, aliás, a faltar o primeiro, é evidente que deve ser aplicado o segundo. Para usar imagens, diremos que o direito positivo não destrói, mas recobre, ou submerge o direito natural; se, portanto, há um 'buraco' no direito positivo, através deste se vê aflorar o direito natural; ou, se preferir, a 'submersão' do direito natural não é total, porque, acima do nível do direito positivo, algumas ilhotas ainda afloram". BOBBIO, Norberto. O Positivismo Jurídico, p.42.

${ }^{30}$ BOBBIO, Norberto. Idem, p. 236.

31 É mais correto dizer que a dogmática jurídica constitui um "sub" paradigma, estando inserida no paradigma filosófico do sujeito, que, mesmo caracterizado pelo jusnaturalismo, abre caminho para 0 juspositivismo, na medida em que traz o método cartesiano, o idealismo e a distinção entre moral e direito. Conforme afirma Ludwig, "a idéia de sistema como método, presente nas teorias jurídicas do século XIX, particularmente no desenvolvimento da Dogmática Jurídica, manifesta a continuidade da elaboração jusnaturalista dos séculos XVII e XVIII: as regras jurídicas são referidas a um ou alguns princípios e daí deduzidas". (LUDWIG, Celso. A Alternatividade Jurídica na Perspectiva da Libertação: uma leitura a partir da filosofia de Enrique Dussel, p.51). 
sistema da civil law, ou indiretamente, pela expressão dos juízes, no sistema da common law. O monismo estatal é, segundo Ehrlich, sustentado por quatro momentos em que a presença do Estado é marcante: no ato de legislar, na administração da justiça, no poder de mando sobre os órgãos estatais e na concepção de que o direito só é possível se houver a força da coação. ${ }^{32}$ Para Coelho, este é o primeiro e mais importante pressuposto ideológico do direito, culminando em uma concepção de Estado como "ser a-histórico e neutro, ubicado acima do social e das misérias da condição humana”, ${ }^{33}$ referindo-se à racionalidade formal que legitima o Direito pelo mero cumprimento de determinadas formas, passando a ser o conteúdo e sua própria experiência histórica considerados externos e irrelevantes ao fenômeno jurídico. Trata-se de uma abordagem avalorativa, que concebe o direito como fato e sem quaisquer juízos de valor.

A necessidade de positivação da norma para que ela tenha validade é conseqüência lógica do mesmo processo: na medida em que apenas o Estado pode produzir legalidade, somente a lei posta por ele próprio pode ser considerada válida. Segundo Bobbio, "dar prevalência à lei como fonte do direito exprime uma concepção específica deste último, que é compreendido como ordenamento racional da sociedade". ${ }^{34} \mathrm{O}$ direito não poderia ter como fonte, nesse sentido, comandos "individuais" ou "ocasionais", pois isso significaria um verdadeiro "caos" social.

A transição das relações de servilismo do sistema feudal para as relações de força de trabalho assalariada exigiu do Direito - enquanto teoria e prática - uma resposta à necessidade de se viabilizar a produtividade econômica, o que se concretizou pela individualização dos conflitos através da criação, durante os séculos seguintes, de institutos abstratos e com pretensão de universalidade, entre os quais se destaca como a mais importante formulação teórica de então a figura do "sujeito de direito".

A categoria dos "sujeitos de direito" é uma construção doutrinária historicamente ligada à formação de uma "subjetividade moderna" e à necessidade de se viabilizarem as trocas mercantis após o fim da era feudal, ${ }^{35}$ embasadas em

32 ERHLICH, Eugen. Fundamentos de Sociologia do Direito, p.110-111.
${ }^{33}$ COELHO, Luiz Fernando. O Estado Singular e o Direito Plural, Revista da Faculdade de Direito da UFPR, n. 25, Curitiba, 1989, p.146.

\footnotetext{
${ }^{34}$ BOBBIO, Norberto. O Positivismo Jurídico, p.119.

${ }^{35}$ MIAILLE, Michel. Uma Introdução Crítica ao Direito, p.110.
} 
uma relação entre sujeitos formalmente iguais. Não se imagina mais um direito sem um sujeito que o exerça, razão pela qual afirma Fonseca ser a modernidade o "lugar privilegiado de ascensão do direito subjetivo" ${ }^{36}$ Nesse sentido, Santos ressalta a importância da individualização dos conflitos para ocultação da diversificação de classes e culturas em uma sociedade estratificada, sendo "nesta sonegação das restantes dimensões (supra-individuais) que reside o caráter ideológico da construção jurídica capitalista" ${ }^{37}$

Os dogmas da individualização dos conflitos e do monismo estatal se fundaram no suposto "caos" que decorreria do "arbítrio individual", e acabaram justificando a rejeição da possibilidade de produção da legalidade por coletividades e associações sociais não necessariamente vinculadas ao poder estatal; fenômeno intensamente presente na experiência histórica da periferia do sistema capitalista.

\section{CRISE DA DOGMÁTICA JURÍDICA NA REALIDADE CONTEMPORÂNEA}

Se hodiernamente não temos mais o colonialismo ${ }^{38}$ explícito como eixo central da economia global, mas sim a globalização e suas diversas dimensões sociais, políticas, culturais e econômicas, cumpre destacar que não há "uma globalização", mas sim "globalizações", sendo cada uma um processo "pelo qual determinada condição ou entidade local estende a sua influência a todo o globo e, ao fazê-lo, desenvolve a capacidade de considerar como sendo local outra condição social ou entidade rival". 39 Santos distingue assim o "localismo globalizado", processo pelo qual fenômenos locais são levados a grandes coletividades, como, por exemplo, na atual influência exercida pela cultura norte-americana; e o "globalismo localizado", quando necessidades ligadas à transnacionalização da economia fazem com que as comunidades locais sejam obrigadas a alterar suas

\footnotetext{
${ }^{36}$ FONSECA, Ricardo Marcelo. Modernidade e Contrato de Trabalho, p.72.

37 SANTOS, Boaventura de Sousa. O Discurso e o Poder, p.92-93.
}

${ }^{38}$ Vale destacar nesse sentido o pós-colonialismo, que é, segundo Boaventura Santos, um conjunto de correntes teóricas que priorizam em suas análises a relação de exploração entre Norte e Sul para compreensão do mundo contemporâneo, considerando que o encerramento formal do colonialismo não o encerrou enquanto relação social e econômica de dependência. A perspectiva pós-colonial parte da idéia de que na margem e na periferia as estruturas de saber e poder são mais visíveis. (SANTOS, Do Pós-Moderno ao Pós-Colonial. E para além de um e outro, p.8-9).

${ }^{39}$ SANTOS, Boaventura de Sousa. Por uma concepção multicultural de direitos humanos, p.433. 
condições e a reestruturar seu modo de vida. Os países centrais têm se apresentado como grandes pólos de localismos globalizados, enquanto à periferia do sistema capitalismo tem restado a adaptação a um ou outro globalismo localizado. ${ }^{40}$

Nesse contexto, dogmas fundamentais da teoria geral do Direito têm passado por uma especial crise de validade e legitimidade, especialmente na realidade latino-americana. $\mathrm{O}$ monismo jurídico, por exemplo, assiste impotente à criação de mecanismos paralelos de resolução de conflitos em todos os estratos econômicos da sociedade. ${ }^{41}$ A epistemologia positivista não encontra soluções diante de conflitos coletivos, em que o dogma da individualização do sujeito simplesmente não serve, como, por exemplo, nos casos de invasão de imóveis rurais e urbanos, criando tensões em torno do direito de propriedade ${ }^{42}$.

Nas palavras de Faria,

a dogmática passa a enfrentar dificuldades insuperáveis para lidar com a crescente flexibilidade dos sistemas jurídicos e com sua progressiva capacidade de adaptação a tensões e conflitos de natureza coletiva. Porque tais tensões e conflitos já não se encaixam nos estreitos limites das soluções individualizadoras forjadas a partir das codificações do século XIX. ${ }^{43}$

Nesse sentido, verifica-se que no caso das invasões urbanas, por exemplo, a aplicação da legislação significa o uso de força policial para desalojar os invasores, o que certamente agravaria a crise de legitimidade do Estado junto à ampla parcela da população que não tem condições de adquirir um terreno próprio; e por outro lado, a não aplicação da legislação implicaria o reconhecimento pelo próprio poder estatal da inutilidade do que seria a única fonte válida de mecanismos de resolução dos conflitos. Assim, conclui Falcão que a pretensão de exclusividade do direito estatal depende "do nível de sua eficácia real, que por sua vez é condicionada pelo

${ }^{40}$ SANTOS, Boaventura de Sousa. Por uma concepção multicultural de direitos humanos, p.436.

${ }^{41}$ Para mais informações sobre mecanismos paralelos de resolução de conflitos nos extratos mais ricos e pobres da sociedade, ver, respectivamente: FARIA, José Eduardo (Org.). Direito e Globalização Econômica. São Paulo: Malheiros, 1998; e SANTOS, Boaventura de Sousa. O Discurso e o Poder. Sérgio Fabris.

42 Nesse sentido ver: FALCÃO, Joaquim de Arruda. Justiça Social e Justiça Legal: Conflitos de Propriedade no Recife. In: FALCÃO, Joaquim de Arruda (Org.). Conflito de Direito de Propriedade - Invasões Urbanas, p.79-101.

${ }^{43}$ FARIA, José Eduardo. Paradigma Jurídico e Senso Comum: Para uma Crítica da Dogmática Jurídica. In: LYRA, Doreodo Araújo (Org.). Desordem e Processo: estudos sobre o Direito em homenagem a Roberto Lyra Filho, p.41. 
grau de legitimidade, donde aceitação consensual do regime político, que produz e aplica o direito", 44 o que cada vez menos se verifica.

Desta permanente crise de legitimidade decorre 0 surgimento de ordenamentos jurídicos não-estatais, configurando, assim, situações de pluralismo jurídico, quando vigora no mesmo espaço geopolítico mais de uma ordem jurídica, ${ }^{45}$ possibilidade defendida por Wolkmer em sua vertente comunitário-participativa a partir da legitimação da experiência histórica e da prática cotidiana concreta de sujeitos coletivos de direito. ${ }^{46}$ Para Coelho, o fundamento do pluralismo estaria no "reconhecimento histórico de uma produção jurídica autônoma, dos grupos microsociais oprimidos, porém ascendentes, aliado à relatividade histórica do direito nacional". 47

Sobre o argumento da coatividade, que afirma caracterizar-se o direito estatal como único direito pelo monopólio do uso da força, afirma Weber ser inadmissível "que se fale só de 'direito' quando, graças à garantia da autoridade política, se disponha de coação jurídica" ${ }^{48}$ No mesmo sentido, Erhlich parte do princípio de que de todas as normas, sejam elas jurídicas, morais, religiosas ou da moda, emanam alguma forma de coação. A força coativa de todas as normas sociais, portanto, provém das comunidades de que fazemos parte e das associações sociais. ${ }^{49}$ A pena e a execução judiciária ocupariam, no conjunto de fatores que levam o indivíduo a respeitar as normas sociais, posição secundária, ocorrendo somente quando os outros meios de coação social já houvessem falhado. ${ }^{50}$ Segundo Weber, o respeito às normas jurídicas não ocorre porque se tratam tais normas de

\footnotetext{
${ }^{44}$ FALCÃO, Joaquim de Arruda. Justiça Social e Justiça Legal: Conflitos de Propriedade no Recife. In: FALCÃO, Joaquim de Arruda (Org.). Conflito de Direito de Propriedade - Invasões Urbanas, p.84.

45 SANTOS, Boaventura de Sousa. Notas sobre a história jurídico-social de Pasárgada. In: SOUSA JR. (org.), José Geraldo de. Introdução Crítica ao Direito: o Direito achado na Rua, v.1, Universidade de Brasília, p. 42: "Esta pluralidade normativa pode ter uma fundamentação econômica, rácica, profissional ou outra; pode corresponder a um período de ruptura social como, por exemplo, um período de transformação revolucionária; ou pode ainda resultar, (...), da conformação específica do conflito de classes numa área determinada da reprodução social".

${ }^{46}$ WOLKMER, Antônio Carlos. Pluralismo Jurídico, p.233-236.

${ }^{47}$ COELHO, Luiz Fernando. O Estado Singular e o Direito Plural. Revista da Faculdade de Direito, n.25, Curitiba, 1989, p.159.

48 WEBER, Max. Ordem Jurídica e Ordem Econômica, Direito Estatal e Extra-Estatal. In: SOUTO, Cláudio e FALCÃO, Joaquim (Org.). Sociologia e Direito, p.144.

49 EHRLICH, Eugen. Fundamentos de Sociologia do Direito, p.54-55.

${ }^{50}$ EHRLICH, Eugen. Fundamentos de Sociologia do Direito, p.57.
} 
"jurídicas", mas porque "o mundo circundante o aprova e reprova o contrário", ou "por um novo hábito rotineiro às regularidades da vida arraigadas na qualidade de costumes". 51

\section{5 ÉTICA DA LIBERTAÇÃO E O RESGATE HISTÓRICO DE UM DIREITO COMUNITÁRIO E PLURAL}

Diversamente dos estados nacionais europeus, no Brasil o Estado surgiu antes da idéia de sociedade civil ou nação soberana, "instaurado por uma estrutura herdada de Portugal, fundamentalmente semifeudal, patrimonialista e burocrática" ${ }^{52}$ Nessas circunstâncias, é necessário outro olhar sobre os padrões sobre os quais fundou-se a legalidade, visto que, conforme afirma Mascaro, a "associação do Estado português aos interesses da burguesia local produz uma forma de legalidade que, imediatamente, esvazia o caráter técnico e aparentemente neutro da instância jurídica". 53 É que o autoritarismo inerente ao processo de formação do ordenamento jurídico nacional instrumentalizou a legalidade de forma vertical, ${ }^{54}$ impossibilitando a horizontalidade das relações e tornando inócua a igualdade meramente formal. Em concordância, verifica-se que, no Brasil,

(...) somente 46 anos após a promulgação do Código Napoleônico, portanto em 1850, iniciase um processo de transpor para as relações jurídicas os ideais do liberalismo europeu. Essa transposição, no entanto, é feita pela classe dominante com extrema cautela, buscando reconhecimento legal de suas conquistas frente ao poder monárquico, mas cuidando para que não fossem elas objeto de apropriação popular. ${ }^{55}$

A Ética da Libertação descrita por Dussel parte da constatação, empírica e inequívoca, da negação da vida das vítimas do sistema, mesmo que sejam vítimas não-intencionais; e articula a fundamentação de novos critérios de validação e de factibilidade, que servem tanto para a análise crítica da história do Direito no Brasil

51 WEBER, Max. Ordem Jurídica e Ordem Econômica, Direito Estatal e Extra-Estatal. In: SOUTO, Cláudio e FALCÃO, Joaquim (Org.). Sociologia e Direito, p.140.

${ }^{52}$ WOLKMER, Pluralismo Jurídico, p.85.

53 MASCARO, Alysson Leandro. Crítica da Legalidade e do Direito Brasileiro, p.81.

54 MASCARO, Alysson Leandro. Idem, p.85.

55 PRESSBURGER, Miguel. Direito Insurgente: o Direito dos Oprimidos, p.11. 
como para a construção de novos direitos hoje, reconhecendo especialmente nos movimentos sociais a legitimidade de pleiteá-los.

O ponto de partida é a negação da vida humana, a exterioridade das vítimas. A afirmação material da vida, em primeiro lugar, impõe o reconhecimento da vulnerabilidade e das necessidades para a reprodução da vida humana, necessidades sem as quais o sujeito morre. Trata-se do modo de realidade do sujeito desde o nível físico-biológico, econômico-político, e assim por diante, condicionando limites que impõem normativamente uma ordem: "o princípio da obrigação de produzir, reproduzir e desenvolver a vida de cada sujeito humano em comunidade" ${ }^{56}$ A passagem do enunciado descritivo a um princípio normativo se dá por uma fundamentação material, e não pela dedução meramente lógico-formal, o que a diferencia do jusnaturalismo.

Em seguida, a Ética da Libertação busca vincular o momento formal da validação, que busca a formulação de uma norma válida, à pretensão de verdade da afirmação da vida humana no momento material; esta adquire pretensão de universalidade e quer ganhar uma fundamentação não apenas subjetiva, mas intersubjetiva, ${ }^{57}$ vinculada à produção de consenso (todos aceitam a escolha racional do argumento) e à pretensão de verdade do momento anterior. ${ }^{58}$

Nesse sentido, o princípio de validade formal decorre do imperativo de manter e defender a vida, visto que esta é condição de possibilidade de tudo mais; e a validação na esfera política exige a "participação simétrica dos cidadãos como sujeitos autônomos na comunidade de comunicação política" ${ }^{59}$

A partir da constatação de que há, efetivamente, uma imensa multidão de excluídos do acesso a direitos básicos na América Latina, mesmo que não intencionalmente por parte do sistema, fundamenta-se um dever de crítica a toda e qualquer estrutura que impossibilite a reprodução da vida humana, reconhecendo-se

56 LUDWIG, Celso Luiz. Da Ética à Filosofia Política Crítica na Transmodernidade: reflexões desde a Filosofia de E. Dussel. FONSECA, Ricardo Marcelo (Org.). Repensando a Teoria do Estado, p.289-290.

57 Idem, p.294.

${ }^{58}$ Aqui cabe a crítica à Razão Comunicativa, formulada em especial por Jurgen Habermas: "Em relação à razão comunicativa há o reconhecimento de sua importância na formulação do princípio de universalidade, desde a intersubjetividade, superando a razão monológica de estilo kantiano. Porém, sua compreensão restritiva do conteúdo material (ausência de pretensão de universalidade) implicou na fundamentação reducionista de um conceito meramente formal ou consensual de verdade" (LUDWIG, Celso Luiz, Idem, p.296).

59 Idem, p.299. 
o Outro em sua condição de vítima. ${ }^{60}$ Desde a sua perspectiva, "a verdade do sistema passa a ser a não-verdade; a validade, a não-validade; e eficácia, a nãoeficácia, da decisão, da norma, da lei, da ação e/ou da ordem política vigente no sistema, em seus consensos políticos hegemônicos". ${ }^{61}$

Ora, os colonizadores europeus não encontraram, na América Latina e na África, uma "página em branco" no que tange à organização jurídica dos povos nativos; em sentido oposto, foram obrigados a decretar a não-validade dos sistemas que vigoravam para que pudessem substituí-los pelo instrumental jurídico tradicional europeu, a fim de assegurarem sua ação enquanto metrópoles.

Segundo Miaille,

os colonizadores europeus encontraram nos territórios em que se instalavam formas de organização social que ignoravam a noção universalizante e abstrata de sujeito de direito; pelo contrário, as relações pessoais de dependência eram muito fortes, num universo de solidariedade social representado por grupos que iam da família à tribo. (...) foi preciso destruir esta organização social e transformar os indivíduos em sujeitos de direito, capazes de vender a sua força de trabalho ${ }^{62}$.

Traços de práticas jurídicas das vítimas da violência colonizadora com características como a não-oficialidade, informalidade, oralidade e valorização do costume podem ser encontradas em diversas comunidades do Brasil colonial, ao lado da cultura jurídica "alienígena"63 imposta como oficial. Segundo Wolkmer, é essencial o "resgate histórico de um pluralismo jurídico comunitário, localizado e propagado através das ações legais associativas no interior dos antigos 'quilombos' de negros e nas reduções indígenas sob a orientação jesuítica. ${ }^{\text {,4 }}$

Nesse sentido, há o exemplo paradigmático da organização político-jurídica do Quilombo de Palmares, cuja disciplina social fundava-se em uma racionalidade coletivista. Reunindo milhares de escravos que haviam fugido dos engenhos,

${ }^{60}$ Idem, p.307-308.

${ }^{61}$ LUDWIG, Celso Luiz. Da Ética à Filosofia Política Crítica na Transmodernidade: reflexões desde a Filosofia de E. Dussel. FONSECA, Ricardo Marcelo (Org.). Repensando a Teoria do Estado, p.311.

${ }^{62}$ MIAILLE, Michel. Uma Introdução Crítica ao Direito, p.112.

63 WOLKMER, Antônio Carlos. História do Direito no Brasil, p.49. Afirma o autor: "Desde o início da colonização, além da marginalização e do descaso pelas práticas costumeiras de um Direito nativo e informal, a ordem normativa oficial implementava, gradativamente, as condições necessárias para institucionalizar o projeto expansionista lusitano".

${ }^{64}$ WOLKMER, Antônio Carlos. Idem, p. 50. 
adotou-se um sistema de propriedade coletiva da terra ${ }^{65}$ fundado na fertilidade da região, na abundância de mão-de-obra, no trabalho cooperativo e na solidariedade social, tendo como conseqüência uma extraordinária produtividade. ${ }^{66}$ Alfonsin destaca que tal sistema nunca esteve isento de defeitos, mas ao menos nasceu a partir do consenso. ${ }^{67}$

A legitimidade concreta destes sistemas é também destacada por Souza Filho em sua tese sobre a relação entre os povos indígenas e o Direito Estatal:

O Direito de cada uma das nações indígenas, indissoluvelmente ligado às práticas culturais, é o resultado de uma vivência aceita e professada por todos os integrantes. Ao contrário disso, o Direito estatal é fruto de uma sociedade profundamente dividida, onde a dominação de uns pelos outros é o primado principal e o individualismo, o marcante traço característico. A distância que medeia o Direito indígena do estatal é a mesma que medeia o coletivismo do individualismo. ${ }^{68}$

Os indígenas nunca reconheceram a propriedade privada, sendo as terras, os bens e os meios de produção compartilhados de maneira comum. As famílias recebiam a terra em usufruto, devendo entregar à comunidade o excedente, sem, portanto, produção de mais-valia, sendo "uma economia natural e auto-subsistente que se caracteriza como um comunismo primitivo" ${ }^{69} \mathrm{Em}$ violento contraste para com as bases do sistema jurídico que se fortalecia na Europa, os ordenamentos indígenas fundavam-se na propriedade coletiva $^{70}$ e na solidariedade pessoal: todos

65 A propriedade coletiva da terra é própria dos ordenamentos jurídicos africanos, que exerceram grande influência sobre a organização dos negros levados ao Brasil como escravos. Em seu conservador relato sobre as nações africanas, René David afirma que "o trabalho era, mais que um modo de ganhar a vida, uma forma de vida, preordenada em perfeita comunhão com as forças da natureza e comportando e realização de ritos; a idéia de um contrato, pelo qual uma pessoa se compromete a trabalhar para um estranho em troca de um salário, era impensável" (DAVID, René. Os Grandes Sistemas do Direito Contemporâneo, p.509).

${ }^{66}$ FREITAS, Décio. Palmares - a Guerra dos Escravos, p.44.

67 ALFONSIN, Jacques. Negros e Índios: Exemplos de um Direito Popular de Desobediência, hoje refletidos nas invasões de terra. In: Negros e Índios no Cativeiro da Terra, p.21.

${ }^{68}$ SOUZA FILHO, Carlos Frederico Marés de. O Renascer dos Povos Indígenas para o Direito, p.74.

69 CERQUEIRA, Daniel Torres de. A escravatura negra no Brasil Colônia e o pluralismo jurídico no Quilombo de Palmares. In: WOLKMER, Antônio Carlos (Org.). Direito e Justiça na América Indígena: da conquista à colonização, p.211.

70 O sistema da propriedade coletiva foi legitimado pelo direito público castelhano, mas surgiu naturalmente a partir da tradição comunitária dos índios. 
trabalhavam, mas apenas na medida para o atendimento das necessidades, ${ }^{71}$ sendo o trabalho obrigatório e contínuo uma idéia ocidental. Mesmo os diferentes status sociais identificadores dos caciques e dos índios comuns não representavam uma desigualdade no tratamento, pois "na distribuição do produto da atividade social, os caciques tinham as mesmas obrigações e os mesmos direitos dos demais"."72

Destaca-se nesses sistemas, enfim, a "organização igualitária e participativa, tão reclamada, hoje, inclusive por juristas fiéis ao liberalismo econômico, como a única capaz de identificar o Estado democrático". ${ }^{73}$

\section{CONCLUSÃO: PELO RECONHECIMENTO DE NOVAS FONTES E NOVOS CRITÉRIOS DE VALIDADE}

Resta claro que o processo de transposição da teoria geral do Direito em suas pretensões universalizantes e uniformizadoras para o contexto brasileiro e latinoamericano não atendeu nem atende aos critérios e princípios da Ética da Libertação, que se fundamentam no critério material da produção e reprodução da vida humana. $\mathrm{Na}$ medida em que a validade do sistema transfigura-se em não-validade diante das vítimas, pois possui para elas efeitos negativos que impossibilitam a reprodução de sua vida, é necessária uma nova validade intersubjetiva, anti-hegemônica, com conteúdos novos e a partir de fontes alternativas de produção jurídica.

Os movimentos sociais críticos adquirem pretensão crescente de legitimidade "frente à crescente ilegitimidade da ordem política vigente que causa efeitos negativos", ${ }^{74}$ tornando-se referências de resgate da cidadania e luta pelos direitos básicos negados na ordem vigente. Hão de ser reconhecidos como "sujeitos

\footnotetext{
${ }^{71}$ Nesse sentido: "No direito real indígena distinguiam-se 2 (duas) categorias de bens; o 'tupambaé', ou 'coisas de Deus', que consistiam na propriedade de uso coletivo, e o 'abambaé', ou 'coisas do homem', que eram atribuídas ao usufruto individual (familiar). Mesmo as propriedades do 'abambaé', com exceção naturalmente dos bens de consumo, eram tão-somente para disposição enquanto necessário. Inexistia o direito de sucessões". RUSCHEL, Ruy Ruben. Sistema Jurídico dos povos missioneiros. In: WOLKMER, Antônio Carlos (Org.). Direito e Justiça na América Indígena: da conquista à colonização, p.189.

72 RUSCHEL, Ruy Ruben. Sistema Jurídico dos Povos Missioneiros. In: WOLKMER, Antônio Carlos (Org.). Direito e Justiça na América Indígena: da conquista à colonização, p.191.

73 ALFONSIN, Jacques. Negros e Índios: Exemplos de um Direito Popular de Desobediência, hoje refletidos nas invasões de terra. In: Negros e Índios no Cativeiro da Terra, p.21.

74 LUDWIG, Idem, p.316.
} 
coletivos de direito", organizados em torno de suas necessidades reais que adquirem força normativa, criando assim "novos direitos". 75

Diante do reconhecimento do fracasso do dogma que preza pelo exclusivismo das fontes formais, é urgente que o Direito latino-americano se volte a um papel de articulação ${ }^{76}$ pela emancipação dos que são hoje as "vítimas" intencionais e não intencionais do sistema. Deve, enfim, deixar de meramente viabilizar as relações de exploração em suas mais diversas feições, a fim de conferir validade e legitimidade na passagem da necessidade à reivindicação, da carência à consciência política, da marginalidade à cidadania e da existência precária à vida com dignidade.

\section{BIBLIOGRAFIA}

ALFONSIN, Jacques Távora. Negros e Índios: Exemplos de um Direito Popular de Desobediência, hoje refletidos nas invasões de terra. In: SOUZA FILHO, Carlos Frederico Marés de. E outros. Negros e Índios no Cativeiro da Terra. Coleção Seminários n.11. Rio de Janeiro: AJUP, 1989, p.17-37.

BOBBIO, Norberto. O Positivismo Jurídico. São Paulo: Ícone, 1995.

COELHO, Luiz Fernando. O Estado Singular e o Direito Plural. Revista da Faculdade de Direito da UFPR, n. 25, Curitiba, 1989.

DAVID, Renè. Os Grandes Sistemas do Direito Contemporâneo. São Paulo: Martins Fontes, 1986.

DUSSEL, Enrique. 1492 - O Encobrimento do Outro. Petrópolis: Vozes, 1993.

ERHLICH, Eugen. Fundamentos de Sociologia do Direito. Brasília: EdUnB, 1986.

FALCÃO, Joaquim de Arruda. Justiça Social e Justiça Legal: Conflitos de Propriedade no Recife. In: FALCÃO, Joaquim de Arruda (Org.). Conflito de Direito de Propriedade - Invasões Urbanas. Rio de Janeiro: Ed. Forense, 1984, p.79-101.

FARIA, José Eduardo. Paradigma Jurídico e Senso Comum: Para uma Crítica da Dogmática Jurídica. In: LYRA, Doreodó Araújo (Org.). Desordem e Processo: estudos sobre o Direito em homenagem a Roberto Lyra Filho. Porto Alegre: Sérgio Antonio Fabris Editor, 1986.

FONSECA, Ricardo Marcelo. Modernidade e Contrato de Trabalho: do sujeito de direito à sujeição jurídica. São Paulo: Ltr, 2002.

FREITAS, Décio. Palmares- a Guerra dos Escravos. Porto Alegre: Mercado Aberto, 1987.

75 WOLKMER dedica um capítulo inteiro a este tema em sua obra Pluralismo Jurídico, "Cap.3. As Fontes de Produção na Nova Cultura Jurídica", p.119-168. 
GALEANO, Eduardo. As Veias Abertas da América Latina. 41.ed. Rio de Janeiro: Paz e Terra, 2002.

IANNI, Octavio. Escravidão e Racismo. São Paulo: Editora Hucitec, 1978.

KUHN, Thomas. A Estrutura das Revoluções Científicas. São Paulo: Perspectiva, 1992.

LUDWIG, Celso Luiz. A Alternatividade Jurídica na Perspectiva da Libertação: uma leitura a partir da filosofia de Enrique Dussel. Curitiba: 1993, UFPR, Dissertação (Mestrado em Direito).

LUDWIG, Celso Luiz. Da Ética à Filosofia Política Crítica na Transmodernidade: reflexões desde a Filosofia de E. Dussel. FONSECA, Ricardo Marcelo (Org.). Repensando a Teoria do Estado. Belo Horizonte: Fórum, 2004, p. 283-325.

LUDWIG, Celso Luiz. Paradigmas da Filosofia. Texto. Universidade Federal do Paraná, Curitiba, 2003.

MASCARO, Alysson Leandro. Crítica da Legalidade e do Direito Brasileiro. São Paulo: Quartier Latin, 2003.

MIAILLE, Michel. Uma Introdução Crítica ao Direito. Lisboa: Moraes, 1979.

PRESSBURGER, Miguel. Direito Insurgente: o Direito dos Oprimidos. In: ARRUDA Jr., Edmundo (Org.). Lições de Direito Alternativo. São Paulo: Acadêmica, 1991.

RIBEIRO, Darcy. O Povo Brasileiro: A formação e o sentido do Brasil. São Paulo: Companhia das Letras, 1995.

SANTOS, Boaventura de Sousa. A Crítica da Razão Indolente: contra o desperdício da experiência. 3.ed. São Paulo: Cortez, 2001.

SANTOS, Boaventura de Sousa. Do Pós-Moderno ao Pós-Colonial. E para além de um e outro. Texto apresentando no VIII Congresso Luso-Afro-Brasileiro de Ciências Sociais. Coimbra, 16 a 18 de Setembro de 2004. Disponível em: http://www.ces.uc.pt/misc/do_pos-moderno_ao_pos-colonial.pdf

SANTOS, Boaventura de Sousa. Notas sobre a história jurídico-social de Pasárgada. In: SOUSA JR. (Org.), José Geraldo de. Introdução Crítica ao Direito: o Direito achado na Rua. V.1. Brasília: Universidade de Brasília, 1993.

SANTOS, Boaventura de Sousa. O Discurso e o Poder. Porto Alegre: Fabris, 1988.

SANTOS, Boaventura de Sousa. Por uma concepção multicultural de direitos humanos. In: (Org.). Reconhecer para libertar: os caminhos do cosmopolitismo cultural. Rio de Janeiro: Civilização Brasileira, 2003.

SOUZA FILHO, Carlos Frederico Marés de. O Renascer dos Povos Indígenas para o Direito. Curitiba: Juruá Editora, 2004.

${ }^{76}$ WOLKMER, Pluralismo Jurídico, p.160-161. 
WEBER, Max. Ordem Jurídica e Ordem Econômica, Direito Estatal e Extra-Estatal. In: SOUTO, Cláudio e FALCÃO, Joaquim (Org.). Sociologia e Direito. São Paulo: Pioneira Editora, 1980, p.139146.

WOLKMER, Antônio Carlos (Org.). Direito e Justiça na América Indígena: da conquista à colonização. Porto Alegre: Livraria do Advogado, 1998.

WOLKMER, Antônio Carlos (Org.). História do Direito no Brasil. Rio de Janeiro: Forense, 1999.

WOLKMER, Antônio Carlos (Org.). Pluralismo Jurídico: Fundamentos de uma nova cultura no Direito. 3.ed. São Paulo: Alfa Omega, 2001. 